\title{
Variations in banana properties
}

\author{
R. Baini ${ }^{1}$ - T. A. G. Langrish $^{2}$ - M. R. Rahman ${ }^{1}$ N. S. Ahmad Zauzi ${ }^{1}$. \\ N. Abdul Rahman ${ }^{1}$
}

Received: 26 April 2016 / Accepted: 17 January 2017

(C) Springer Science+Business Media New York 2017

\begin{abstract}
Samples prepared from different bananas and from different parts of a banana may vary in their properties, which may cause variations in the final results in experiments. Therefore, assessment of variation in the samples' properties is necessary, and it can be evaluated using statistical analysis. In this work, the variation in banana properties-colour, texture, moisture and sugar contentswithin and between bananas were assessed statistically using a two-stage nested design test and the two-sample t-test. Results show that the variation of properties is significant for bananas with different degrees of ripeness. This finding suggests that samples can be prepared from different parts of the bananas provided that the bananas are at the same degrees of ripeness. It was also found that the location of sample in the drying chamber did not affect the measured properties of the drying bananas, significantly. The tests performed for banana texture using a laboratory apparatus produced results that were similar to those performed using a dynamic mechanical analyzer. This suggests that the use of highly-sophisticated instruments in the texture analysis of dried fruit in terms of the apparent modulus is not crucial.
\end{abstract}

Keywords Variation - Statistical analysis - Banana properties $\cdot$ Colour $\cdot$ Texture $\cdot$ Moisture content $\cdot$ Sugar content $\cdot$ Drying

R. Baini

ruby@unimas.my

1 Department of Chemical Engineering and Energy

Sustainability, University Malaysia Sarawak, Kota Samarahan, Sarawak, Malaysia

2 School of Chemical and Biomolecular Engineering, The University of Sydney, Sydney, NSW, Australia

\section{Introduction}

The measurements of properties, such as colour and texture, of fruit samples in drying experiments (with similar drying conditions) give variable results due to biological variability within and between the samples used. For example, those samples prepared from different bananas and from different parts of a banana may vary in their properties. These variations in the properties of bananas may be due to the different degrees of ripeness and the locations where the bananas are grown. The average drying behaviour of bananas in terms of their moisture loss as functions of time has often been studied [1-5] but the texture and variability of samples has not been studied in detail. Foster et al. [6] measured the chemical compositions-the contents of moisture, ash, fiber, sugar, ascorbic acid, $\mathrm{Fe}, \mathrm{Cu}$, $\mathrm{Zn}, \mathrm{Mn}, \mathrm{Na}, \mathrm{K}, \mathrm{Ca}$ and $\mathrm{Mg}$-in the different parts within a banana, and they found that the distribution of nutrients measured in the banana samples vary. Hardisson et al. [7] has evaluated the variation in the mineral compositions of bananas, which are grown in different locations. They measured the levels of $\mathrm{Na}, \mathrm{Ca}, \mathrm{Mg}, \mathrm{Cu}, \mathrm{Zn}$ and $\mathrm{Mn}$ in bananas, which were grown in the north and south island of Tenerife, Spain, and found significant variations in the measured components. Variation in moisture content also exists in timber drying [8] because timber that is prepared from different parts of trees or different trees may have different moisture content. Timber is usually being dried before it can be used to make furniture; Moisture content variation in timber has been found to affect the final quality of dried timber, and hence it can affect the final quality of furniture produced. Effect of variation in the properties of biological material has also been studied by Cabardo and Langrish [9] for Blackbutt Timber. In their study, analysis of variance showed that the board positions within-trees 